Article

\title{
Analysis of the Influence of Diesel Spray Injection on the Ignition and Soot Formation in Multiple Injection Strategy
}

\author{
Raul Payri ${ }^{1, *(1)}$, José M. García-Oliver ${ }^{1}{ }^{1}$, Victor Mendoza ${ }^{1}$ and Alberto Viera ${ }^{2} \mathbb{C}$ \\ 1 CMT-Motores Térmicos, Universitat Politècnica de València, Edificio 6D, 46022 Valencia, Spain; \\ jgarciao@mot.upv.es (J.M.G.-O.); vicmena1@mot.upv.es (V.M.) \\ 2 AVL Ibérica SA, Edificio El Rengle Núcleo D, 08302 Mataró, Barcelona, Spain; albertoviera@gmail.com \\ * Correspondence: rpayri@mot.upv.es
}

Received: 4 June 2020; Accepted: 4 July 2020; Published: 7 July 2020

\begin{abstract}
Multiple injection strategies have increased their capabilities along with the evolution of injection system technologies up to the point that nowadays it is possible to inject eight different pulses, permitting to improve the engine performance, and consequently, emissions. The present work was realized for two simplified strategies: a pilot-main and a main-post, in order to analyze the influence of an auxiliary pulse on the main and otherwise, in reactive conditions for two pilot/post quantities and four hydraulic dwell times. The study was carried out by employing two optical techniques: diffused back-illumination with flame bandpass chemiluminescence for measuring soot, represented by soot-maps distribution, and single-pass schlieren for ignition delay (ID). Furthermore, a novel methodology for decoupling the start of combustion (SOC) of the second pulse was developed and successfully validated. From the ignition delay results, it was found for all test points that the pilot injection enhanced conditions, which promote a faster ignition of the main pulse, also at higher chamber temperatures, all conditions presented a separate combustion event for each injection. In emission terms, soot increased in the pilot-main strategies compared to its single injection case, as well as, in conditions that promote faster-premixed combustion.
\end{abstract}

Keywords: multiple injections; combustion; diesel; spray; ignition; optical techniques

\section{Introduction}

Over the years, researchers have studied the fundamental processes involved in diesel direct injection and how they impact crucial variables affecting the engine performance and especially pollutant formation, since regulations on engine emissions have considerably become more rigorous. One key factor for controlling pollutant emissions is diesel combustion process, which in turn, is a complex phenomenon affected by numerous mechanisms [1], as it is the diesel spray mixing, which has been recognized as a critical factor in combustion control [2]. In an effort for reducing emissions from the injection-combustion field, several techniques have been developed. One such strategy is multiple injection, which has been proven being useful for lowering fuel consumption and contaminants [3].

Multiple injections strategies aim to deliver the same mass of fuel as in a single injection, in order to, at least, not increase the consumption. But contrarily to a single injection, they permit the using of up to eight injection pulses, meaning eight different quantities that can be injected in one cycle [4]. This is a key advantage of this strategy because more pulses provide more flexibility, and different mass-distribution strategies can be followed, which also have different names. For example, split injections usually refer to pulses with similar mass. Another interesting strategy 
is the early-pilot-post-late, which is made up of a main injection, which delivers the largest mass, together with two smaller pulses before (pilot) and after (post) the main injection. The first injection event modifies the conditions in the chamber in which the second develops, and hence combustion performance. For these reasons, the proper management of the mass distribution and the separation between the mass flow rate pulses, denominated dwell time (DT), can lead to a better control over the heat released, air-fuel mixing process, and consistently, soot formation.

Soot emission in diesel combustion is determined by a competition between its formation and oxidation [5]. The combustion is generally characterized by three phases: ignition delay (ID), premixed combustion, and diffusive combustion [6]. The first phase is defined as the interval from the start of injection (SOI) until the start of combustion (SOC). In the second phase, the premixed fuel that has not combusted is burned thanks to an abrupt liberation of heat. Finally, in the third phase, the heat is released as the fuel-air mixing process happens. From there on, the combustion flame is set near the spray head around the maximum heat release rate and propagates upstream to the nozzle up to the lift-off length (LOL) [7-9]. The momentum provided by the injection is the backbone of the whole process, as it drives the mixing mechanisms that bolster the diffusion flame, as well as, atomization, air entrainment, and evaporation of the spray.

Diesel ignition deeply depends on the spray characteristics and can be summarized in three stages according to Higgins et al. [10]. Firstly, physical induction that is steered by the air fuel mixture formation. Then, the first-stage ignition, also called coolflames, that is distinguished by the rise in chamber pressure and first noticeable chemiluminescence. Lastly, the second-stage ignition, when the rapid heat release triggers the premixed burn.

Several authors have reported the contributions of multiple injections to simultaneously reduce diesel NOx and soot emissions [3], for example, the positive effect that split injections have on the air-mixing process. Additionally, $\mathrm{O}^{\prime}$ Connor and Musculus [11] reported the reduction of soot with the inclusion of a post injection. Thence, describing how variables that can be controlled are related to the mechanisms involved in emissions is a helpful step for designing better strategies to accomplish the engine power requirements and stringent stipulations imposed. In this sense, this document provides an experimental methodology to study the effects on combustion of two simplified multi-injection strategies: pilot-main and main-post injections, in order to develop a better understanding of the interaction between pulses. The technology evolution, as well as the development of new optically accessible test rigs [12], make it possible to carry out fundamental studies of the injection event in a simplified environment, with nearly quiescent boundary conditions that can be controlled, nonetheless, the importance of an engine bowl-shaped combustion chamber for the effectiveness in some calculations was also analyzed.

This paper continues previous investigations for the same injector unit and injection scheduling. Payri et al. [13] studied the hydraulic behavior by rate of injection and spray momentum flux measurements for the same multiple injection scheme proposed in the present work. On the other side, Payri et al. [14] performed a spray development analysis in a non-reactive atmosphere in terms of liquid length, and vapor phase penetration, developing a novel technique to obtain the spray penetration even when two separate injection events are present in the same frame.

Despite the knowledge on multiple injections process has increased considerably, the recent schedules of close coupled injections are not as widely known, since they are only achievable by the newer injectors. Some research has been done for these new injection strategies for analyzing the combustion noise, nevertheless, there are still questions about the interaction between pulses, thus, the understanding of the processes inherent to the combustion of these sprays is an interesting field of study addressed in this paper and a natural continuation of the previous related literature mentioned. For this goal, variables of interest to characterize the diesel spray in reactive conditions were obtained using optical techniques. An arrangement of diffused back-illumination (DBI) setup, single-pass schlieren and flame radiation were combined to quantify soot, calculate the approximate ignition 
location and determine the ignition delay in the combustion. To this end, a novel image processing approach to estimate the ignition delay of multiple injection pulses was implemented.

Following this introduction, the next section presents a description of the tools, facilities, and experimental techniques used, followed by the results and analysis, and finally the conclusions.

\section{Materials and Methods}

\subsection{Facility and Injection System}

The installation used for the spray visualization measurements was an optically accessible constant pressure and flow test chamber, such as those described in [15-17], and seen in Figure 1. This facility's test chamber can achieve a nearly quiescent and steady thermodynamic environment that makes it possible to measure with a higher injection frequency compared to a constant volume chamber, and relatively low testing times [18]. The facility emulates conditions found in actual engines, which are possible thanks to a continuous flow of high pressure and temperature gas, fitting the requirements set by the convention introduced by Baert et al. [12].

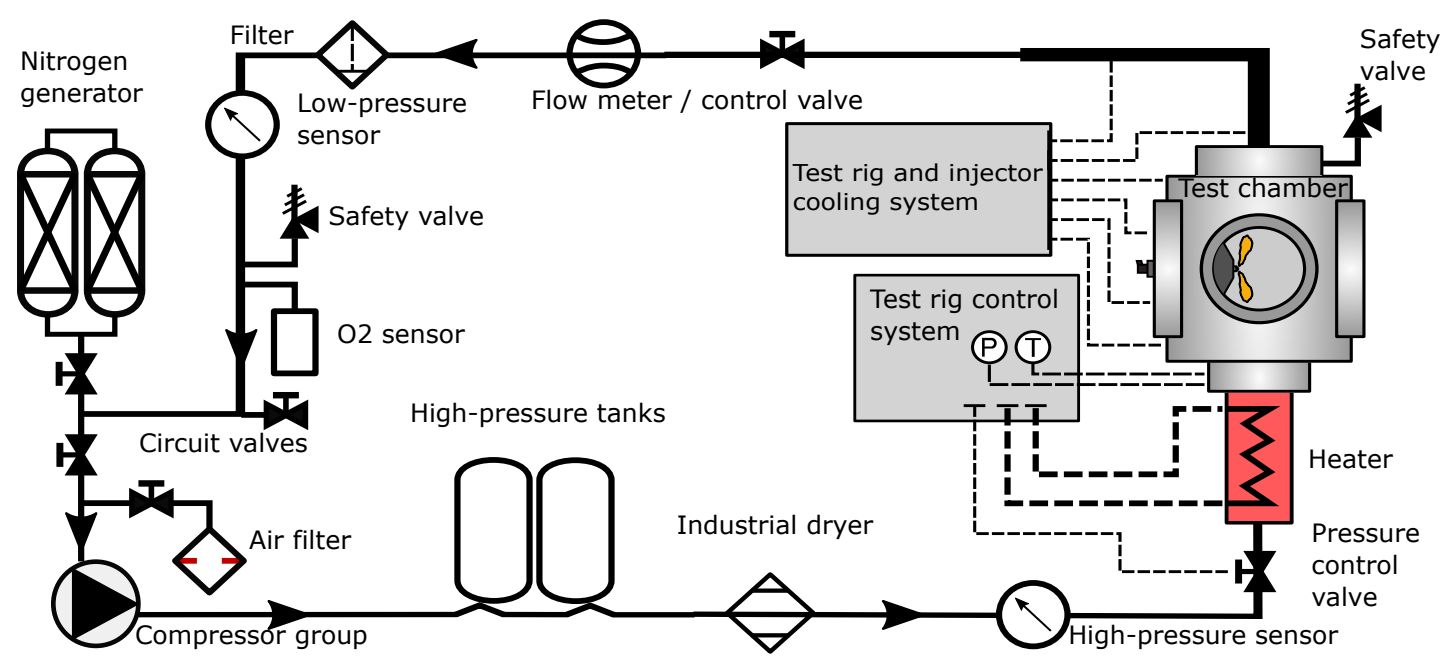

Figure 1. Schematic diagram of the high-temperature and high-pressure facility.

The fuel delivery system was composed of a fuel supply source, a high-pressure unit, a common-rail, and the injector. These were in charge of transporting the fuel at a specific pressure and stable conditions. To this end, commercially available components were adapted for laboratory use. The injection system is explained in more detail in [13].

The injector used is a common-rail (PCR) type 5 from Continental [4] presented in the Figure 2 and the characteristics are detailed in Table 1. Its micro piezo stack actuator improves its efficiency in multiple injection strategies, owing to the maximization of its internal high-pressure volume. The injector was fitted with a custom geometry six hole nozzle, with a spray optically isolated from the others, labeled as spray of interest and numbered as plume 1.

Table 1. Injector properties.

\begin{tabular}{ccc}
\hline Parameter & Value & Units \\
\hline Holes & 6 & - \\
Avg. outlet diameter Do & 90.1 & $\mu \mathrm{m}$ \\
Outlet diameter (Do) & $91.7^{*}$ & $\mu \mathrm{m}$ \\
Avg. k factor & 5.3 & - \\
Nominal flow rate & $313^{* *}$ & $\mathrm{~mL} \mathrm{~min}^{-1}$ \\
Avg. heigth angle & 74.8 & degrees \\
Degree of hydro-erosion & 7.7 & $\%$ \\
* Of the spray of interest. ${ }^{* *}$ At $10 \mathrm{MPa}$ of injection pressure.
\end{tabular}




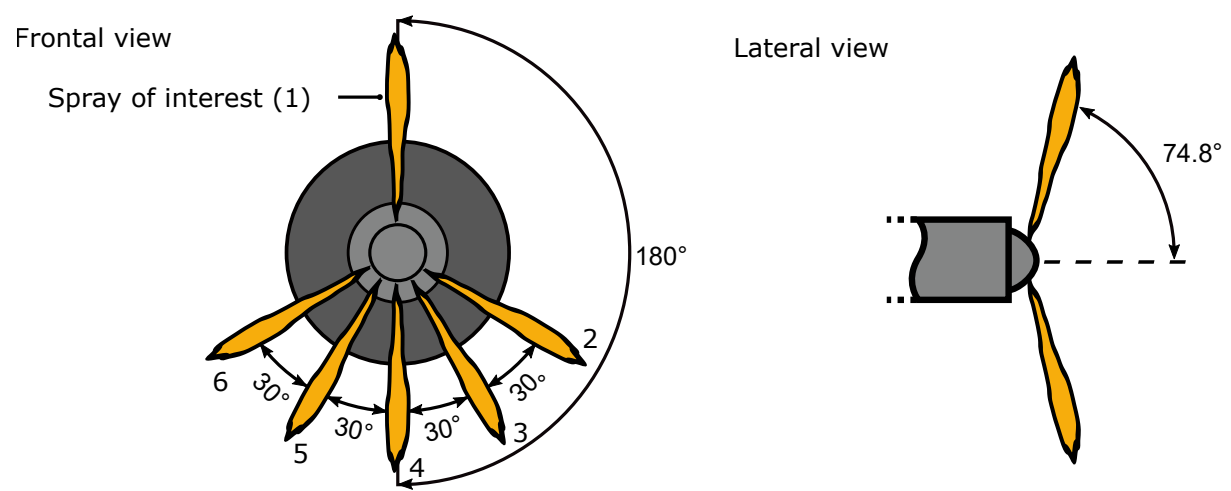

Figure 2. Nozzle configuration of the PCR5 injector.

\subsection{Methodology}

The experimental campaign consisted of performing two multiple injection strategies: a pilot main and a main-post. Furthermore, for comparison effects, a single injection with the total mass of $30 \mathrm{mg}$ (also named as reference case from now on) was measured.

Boundary conditions for the spray visualization were selected following the Engine Combustion Network (ECN) guidelines [19]. The test matrix consisted of 72 test points, with ten recorded injection cycles per condition. For DBI and flame radiation, the number of recorded injection cycles per test point was increased to 20 to improve the statistical robustness of soot measurements. The chamber pressure was set to fulfill the target density for a given ambient temperature, considering atmospheric air for the calculations, which also enabled us to achieve a reactive atmosphere. The test plan is presented in Table 2.

Table 2. Test plan for the reactive spray visualization campaign.

\begin{tabular}{lcc}
\hline Parameter & Value & Units \\
\hline Rail pressure $\left(P_{r}\right)$ & $100-200$ & $\mathrm{MPa}$ \\
Chamber density $(\rho)$ & $15.2-22.8$ & $\mathrm{~kg} \mathrm{~m}^{-3}$ \\
Chamber temperature $(T)$ & $800-900$ & $\mathrm{~K}$ \\
Oxygen concentration & 21 & $\%{ }_{\text {vol }}$ \\
Injector operating temperature & 363 & $\mathrm{~K}$ \\
Pilot/post dwell times & $200-350-500-650$ & $\mu \mathrm{s}$ \\
Pilot/post injected quantity & $1-3$ & $\mathrm{mg}$ \\
Total mass per injection & 30 & $\mathrm{mg}$ \\
Injection frequency & 1 & $\mathrm{~Hz}$ \\
Recorded injection cycles & $10-20$ & - \\
\hline
\end{tabular}

The mass injected, as well as the energizing times used were calculated based on the results achieved in a related previous work [13]. The pilot/post mass distribution was chosen considering typical engine values of $5 \%$ and $10 \%$ of the total injected mass, although in the first case it was reduced to $1 \mathrm{mg}$ to amplify the difference between injected quantities. Dwell times were selected considering a minimum hydraulic separation between injection pulses of $200 \mu \mathrm{s}$, increasing it by increments of 150 up to $650 \mu$ s. Voltage levels and ramp-off (volts per second) were provided by the original equipment manufacturer.

\subsection{Experimental Techniques}

The basics of the optical techniques that allowed us to study the effects of multiple injections in combustion are summarized in the present section and delved deeper in $[14,20,21]$ : 


\subsubsection{Diffused Back-Illumination (DBI)}

This technique has become the standard for liquid length measurements in the ECN [22]. The setup permits line-of-sight visualization, in which light is extinguished due to the optical depth of the spray. When the light passes through the spray, three scenarios can occur: the rays will encounter in its path sprayed fuel in liquid phase and be blocked; the light will find the vapor phase of sprays and be slightly deviated and attenuated; the light will go through a zone where there is only ambient gas and will be undisturbed [23]. This technique can also be used for qualitative or even quantitative measurements of soot concentration [17], which is described further in Section 2.4.1.

\subsubsection{Single-Pass Schlieren}

This technique is widely used for studying the vapor phase of sprays and also the evolution of it as in non-reactive environment vs. reactive.

As explained by Settles [21], the schlieren image responds to the first spatial derivative of the refractive index, namely, light rays travel uniformly through homogeneous media, but, they are bent proportionally to the refractive index of the medium they enter into. In short, this method measures the changes in density gradients in the path of the rays, and by studying the variation of the intensity within the spray boundaries, it is possible to determine the ignition delay, among other variables $[8,9]$.

\subsubsection{Optical Configuration}

Figure 3 shows a sketch of the optical layout used for the experiments. Both DBI and schlieren are simultaneously used to record information of the same injection event, by using adequate synchronization. Two 50:50 beam splitters were required to enable DBI and schlieren setup to access the test section through the same optical accesses, while keeping all optical axes aligned.

The DBI setup used was developed by Ghandhi and Heim [20] and is explained in the work of Viera [24]. It is composed of a light source, a diffuser, a field lens, and a high-speed camera. A blue LED unit was equipped with a parabolic reflector to reduce the light aperture angle from $120^{\circ}$ to $25^{\circ}$ and minimize light loss. Rays then, were directed to a $100 \mathrm{~mm}$ engineered diffuser with $20.5^{\circ}$ of divergence angle. A Fresnel lens, with a focal length of $67 \mathrm{~mm}$ was located such that the diffused illumination source was reproduced near the optical plane of the spray visualized. A blue LED was chosen because it provides flexibility discarding light rays from other optical setups that could interfere with the measurement, as well as it allows for a higher signal-to-noise ratio in soot DBI measurements [25].

For soot concentration additional repetitions were recorded with the DBI setup and the LED light turned off to acquire the flame radiation captured by the filter. Those images are later used to get rid of the incandescence (soot thermal radiation) contribution.

Regarding the schlieren configuration, light from a Mercury-Xenon arc lamp with an output power of up to $1000 \mathrm{~W}$ was passed through a $1.2 \mathrm{~mm}$ opening, to create the point-like illumination source. A $150 \mathrm{~mm}$ biconvex lens was positioned at its focal length of $450 \mathrm{~mm}$ to collimate the rays, which after crossing the test section, are captured by an equivalent biconvex lens and converged to its focal point, where an iris diaphragm with a $4 \mathrm{~mm}$ aperture was set as the cutoff mechanism. Both apertures were selected from previous experimental campaigns with similar testing conditions in the same facility $[8,9]$.

The light pulse from the LED was synchronized with the exposure cycles of the Photron SA-X2 camera (sourced by Photron company, West Wycombe, United Kingdom). In this way, DBI illumination does not interfere with the schlieren configuration, as the exposure event of the SA5 camera occurs in a different time lapse in the frame of the video. However, this does not occur with the schlieren continuous light that can reflect in the optical elements and be visualized in the DBI camera, as well as beam steering effects caused by these reflections. To minimize this potential problem, a narrow band-pass filter of $460 \pm 5 \mathrm{~nm}$ was implemented. Timing for all cameras was referenced to the start of energizing (SOE) of the injector. 


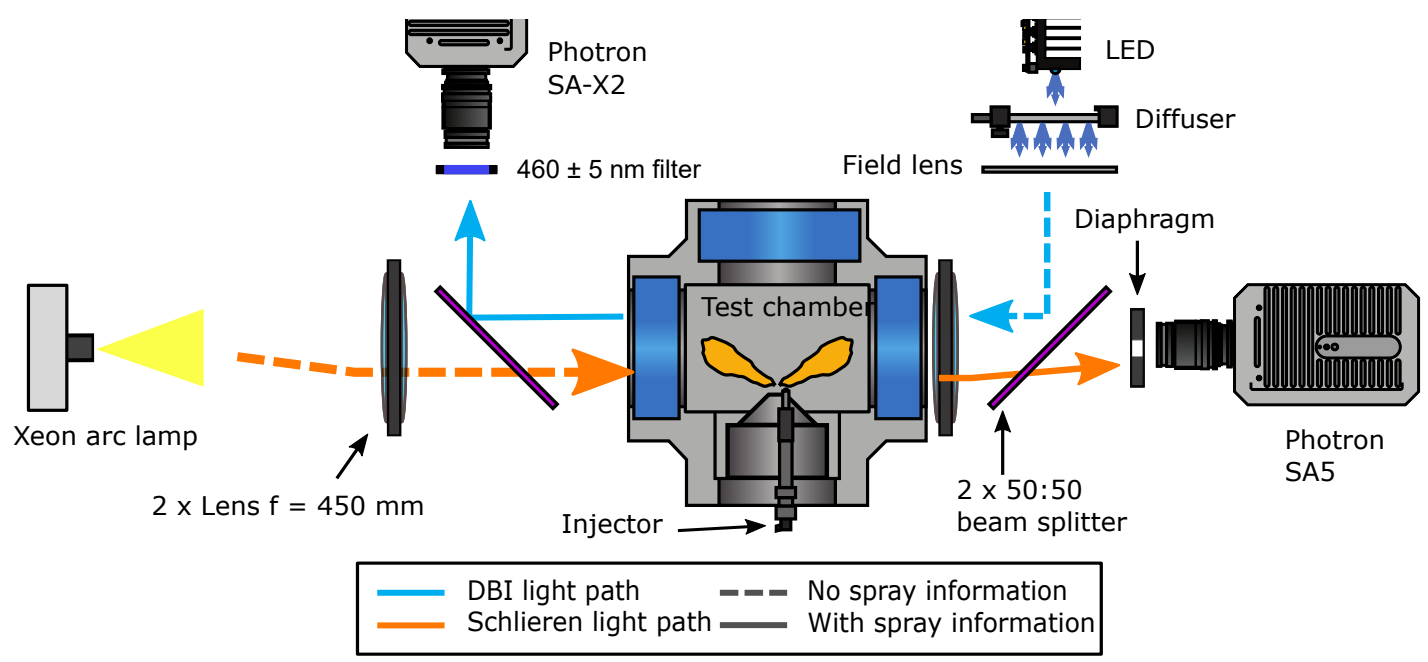

Figure 3. Schematic representation of the optical configuration used for the reactive spray diagnostics.

\subsection{Image Processing Method}

Once the images were obtained, they need to be processed in order to extract the objective information. The processing method usually employed for single injections is divided mainly in two parts. Firstly, extracting the spray image and the background, and secondly a post analysis to determine the parameters of interest. The frequent method stages are briefly defined next, and widely described in previous works $[14,23]$. Furthermore, other specific processing routines were developed in MATLAB for soot DBI.

- Image masking: This consists of providing the processing routine with a region where the spray is located, with the purpose that undesired elements present in the frame are discarded for the segmentation between the background and the rest of the image where the spray exists.

- Background substraction: For DBI images, the background is considered static and is obtained with a simple average of the first few images. Nevertheless, new problems related to this step for the schlieren images and the decoupling of the contour of the pilot or post injections from the main come along with the multiple injection strategies. For instance, some areas in schlieren images belonging to the spray might present pixels with the same intensity levels as the background, that might appear throughout all the injection event. Therefore, other criteria different to the classic was applied, described by Payri et al. [26]. For the first issue, the procedure consists of combining a dynamic-background-composition subtraction that constantly updates the background information $[15,27]$, with an image temporal-derivative approach that works very well for capturing the contour of a spray in the diluted regions [28]. Regarding the decoupling of the schlieren contour, given that the second injection occurs in conditions where density gradients were induced by the previous one, the same dynamic background subtraction strategy was applied to the second pulse, as the non-spray pixels of the composed background contain the image with the first injection, so it is substracted, and the remnant pixels, identified as the spray in the previous frame, were filled with the original background before injection. Additionally, higher binarization threshold was used for the second injection to minimize the probability of over-predicting its boundaries. This procedure is more detailed in [14].

- Contour detection: For DBI movies, a fixed value of optical thickness was used as a threshold of the spray image [25]. In contrast, for schlieren images, the threshold was calculated as a fixed factor multiplied by the dynamic range of the frame being analyzed. Lastly, a filtering process is carried out $[24,26,29]$.

- Contour analysis: The data gathered with the image processing was analyzed with a moving average to assess shot-to-shot dispersion, and obtain a global value for each variable per time 
step $[8,26]$. Additionally, the start of injection (SOI) was obtained to phase the time domain of the results and adequately compare test points $[8,23]$.

\subsubsection{Soot DBI}

For soot DBI processing methodology, two optical techniques were required: DBI itself to directly measure extinction caused by the soot cloud, and flame radiation to correct the incident combustion light. In general, all repetitions are averaged for each optical technique to reduce the impact of stochastic variations, for avoiding the need of doing temporal interpolation, and to reduce the influence of the beam steering (observed in the DBI movies) on the optical thickness calculations [17,30].

It is necessary to take into account that some cameras show problems with fully resetting the sensor after the readout process when recording at high speeds. Hence, a weak ghost image was observed in the flame radiation frames, affecting the correction of the light coming from the combustion. For such reasons, the images were not gathered with methodologies presented by other authors as [9] that recorded alternating frames between the two optical methods, instead, soot extinction movies were recorded in separate injection events, with a higher number of repetitions to improve the statistical robustness of the sample for soot concentration results and minimize the impact of shot-to-shot variations.

The processing started by calculating the repetition-wise average of each movie for each time step. Then, the optical thickness $(\tau)$ was calculated with the Beer-Lambert law (Equation (1)), where I and $I_{f}$ correspond to the current frame of the DBI, and flame radiation of the same time-step respectively, and $\mathrm{I}_{0}$ is the reference illumination estimated as the average of the images before the injection event. An example of the first two of these images is depicted in Figure 4.

Finally, the total optical thickness per axial position was calculated and traced along the spray axis, collapsing to a cross-sectional $\mathrm{KL}$ ( $\mathrm{K}$ is the dimensional extinction coefficient in the equation, and $L_{\text {soot }}$ is the path length through the soot cloud) value per distance. Therefore, conditions with higher soot concentrations present a higher $K L_{\text {soot }}$ factor, nevertheless, it was limited to the dynamic range of the images gathered.

$$
\tau=\ln \frac{I_{0}}{I-I_{f}}=K \cdot L_{\text {soot }}
$$
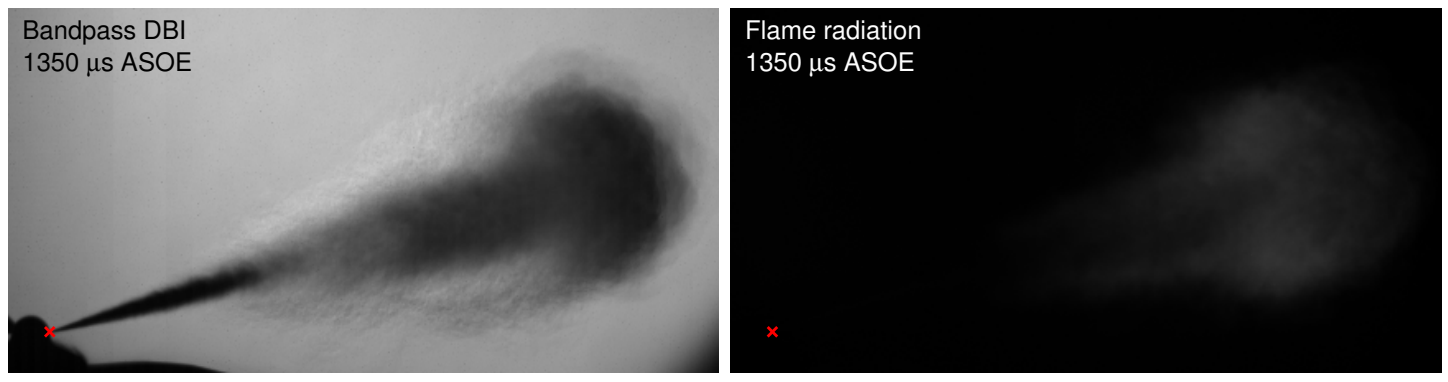

Figure 4. Example of the repetition-wise averaged image for the bandpass diffused back-illumination (DBI) (left) and flame radiation (right) setups. The frames shown are for a single injection event, a rail pressure of $100 \mathrm{MPa}$, a chamber density of $22.8 \mathrm{~kg} \cdot \mathrm{m}^{-3}$, and temperature of $900 \mathrm{~K}$.

\section{Results and Discussion}

The effect of multiple injections parameters as hydraulic dwell time (DT) and fuel quantities distribution on the main variables of combustion given in terms of the ignition delay, approximate ignition location, and soot distribution maps are shown in this section. For most conditions with hydraulic dwell times of $200 \mu$ s for pilot-main, or $200 \mu$ s and $350 \mu$ s for main-post strategies, as well as lowest chamber density and temperature, a clear transition between pulses did not occur, and their contours could not be decoupled; for visualization effects, only one spray was detected. 
This phenomenon did not occur in the hydraulic characterization [13], and the possible causes are discussed in [24].

\subsection{Novel Method for Decoupling the Start of Combustion of the Second Pulse}

In single injections, the start of combustion (SOC) can be identified by the high rate of heat release and the increase in chamber pressure present during the premixed combustion of the second stage, which, from the optical point of view is visualized as a sudden radial expansion [31]. This is valid for the first pulse in multiple injections, nonetheless, this pulse creates local conditions that could promote a faster SOC for the second injection [32] and the radial expansion would be very small [3] or non-existent, as is seen in Figure 5. Besides, once the thermal radiation from soot appeared in the frames, the intensity levels of these pixels resembled the background, creating problems in contour depiction.
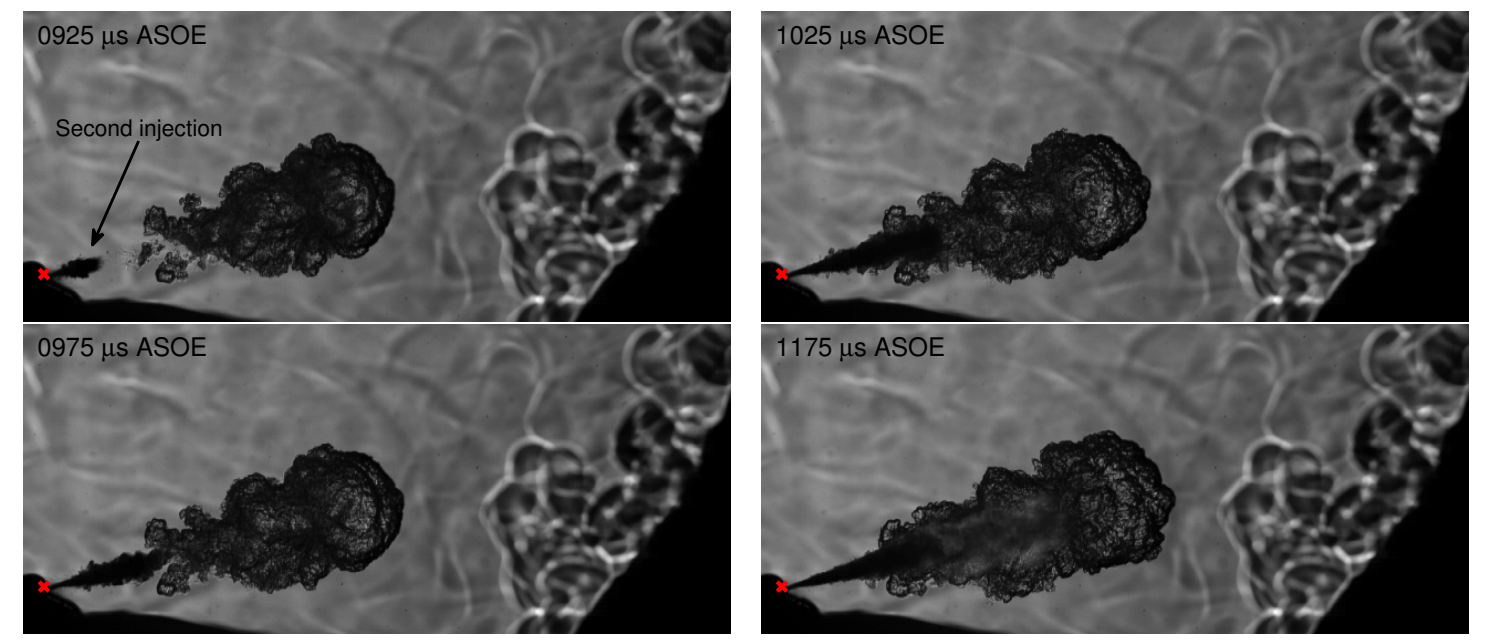

Figure 5. Example of the images gathered through schlieren for multiple injections, starting near the start of injection (SOI) of the second pulse. The frames are for a 1-29 pilot-main event, a dwell time of $350 \mu$ s, rail pressure of $100 \mathrm{MPa}$, chamber density of $22.8 \mathrm{~kg} \cdot \mathrm{m}^{-3}$, and temperature of $900 \mathrm{~K}$.

Motivated by these problems, a different but novel methodology was implemented using movies gathered through DBI in reactive conditions and taking advantage of beam steering effects caused by density gradients created by the combustion that were visible due to combining DBI with single-pass schlieren. DBI images were processed by calculating the total pixel-wise frame-to-frame difference in absolute terms to associate the apparition of soot as a positive contributor. Furthermore, each frame was masked with the steady state liquid length to exclude differences induced by the liquid phase penetration. The Figure 6 shows that with this differentiation is possible to distinguish the second injection, contrarily to what was depicted in Figure 5.

The SOC of the second pulse was in principle obtained from the radial expansion derived from schlieren images if it had a distinguishable premixed phase. However, if no radial expansion was observed, the SOC was linked to the biggest difference between a frame compared to the previous one, which is related to the instants just before the apparition of soot.

For this new method, the SOC was correlated to the local maximum of the absolute frame to frame difference derivative, calculated with a 3-point-stencil (after the SOI). The derivative, named rate of difference (ROD), quantifies the temporal evolution of pixel structures both in growth and intensity, as it is represented in Figure 7 where the ROD is plotted for each of the twenty recorded cycle (different color each) and the second stage of ignition is represented by the maximum ROD. These traces were observed in all the movies when the combustion of the second pulse was decoupled from the first. Additionally, it is possible to observe that for shorter DT the premixed phase duration of the second pulse and intensity is reduced. 

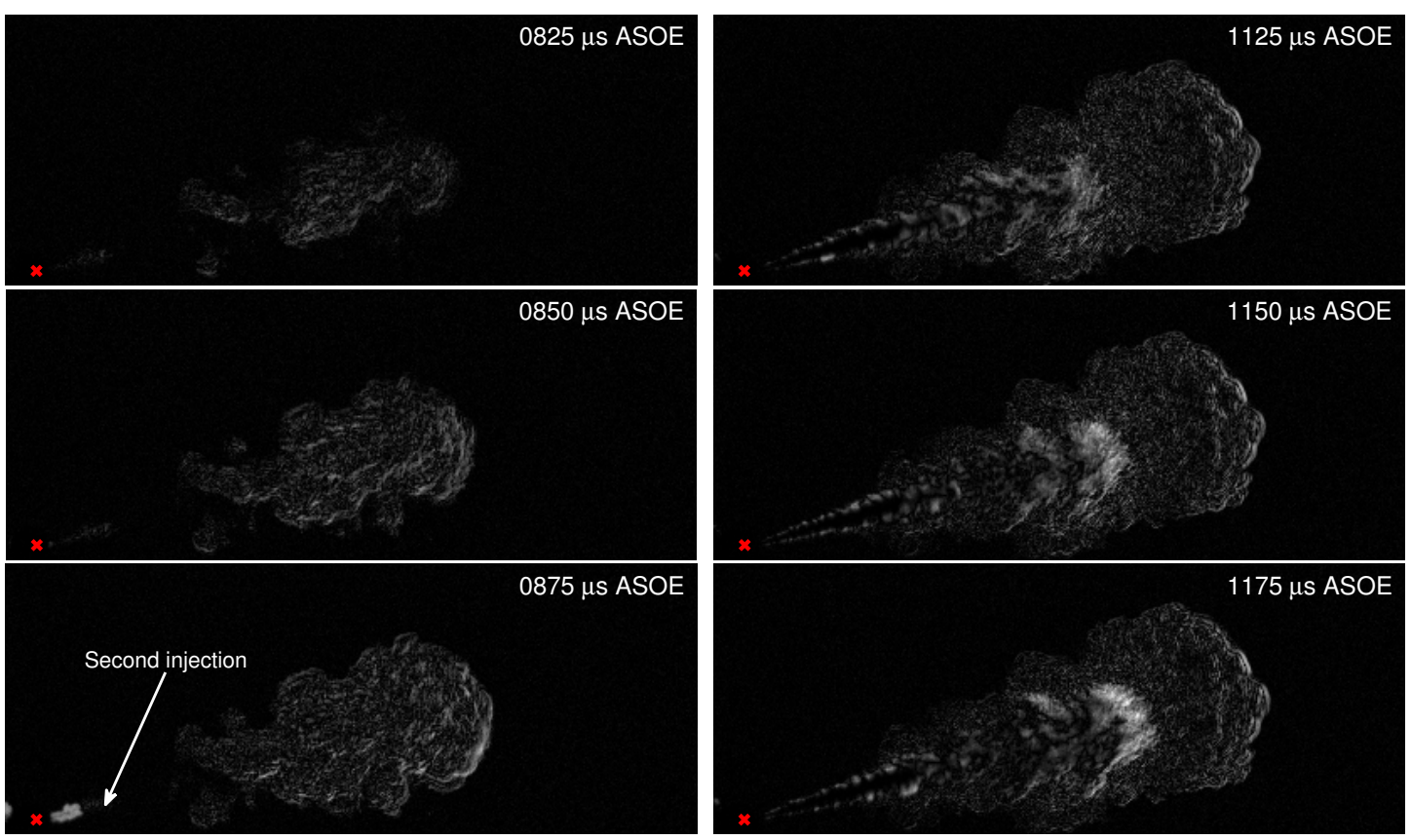

Figure 6. Example of absolute pixel-wise frame-to-frame differentiation for multiple injection. The frames shown are for a 1-29 pilot-main event with a dwell time of $350 \mu$ s, a rail pressure of $100 \mathrm{MPa}$, a chamber density of $22.8 \mathrm{~kg} \cdot \mathrm{m}^{-3}$, and temperature of $900 \mathrm{~K}$.

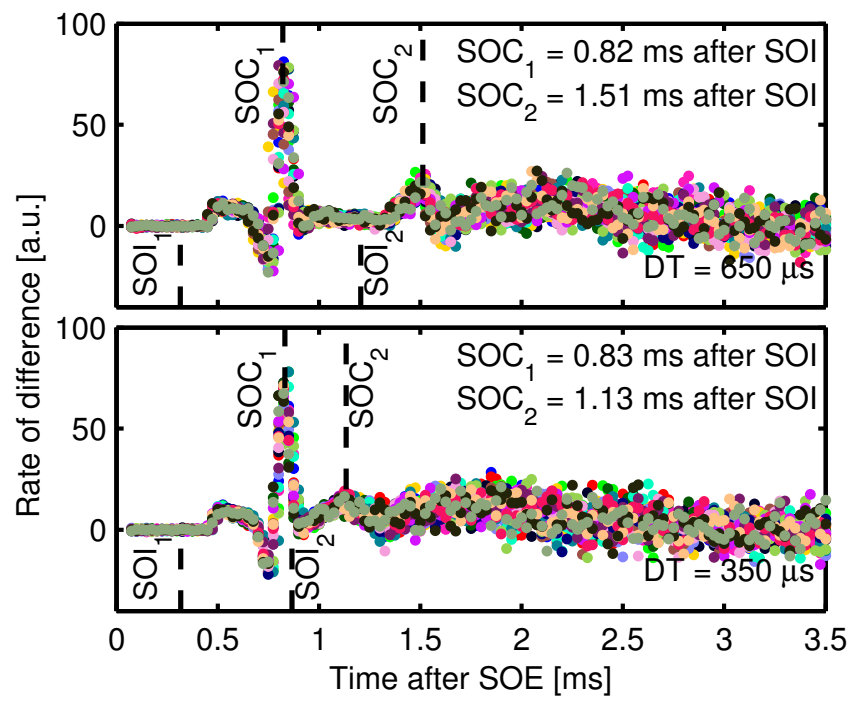

Figure 7. Example of the rate of difference represented by a different color for each cycle. Vertical dashed lines represent either SOI or start of combustion (SOC). Results are for a rail pressure of $100 \mathrm{MPa}$, a chamber density of $22.8 \mathrm{~kg} \mathrm{~m}^{-3}$, and temperature of $900 \mathrm{~K}$.

This method was validated contrasting its results with those of ignition delay calculated for the single injection cases through the schlieren movies. As a result, the contour changes produced by the premixed phase were traced by both methodologies almost identically (see Figure 8). Nevertheless, for single injections this is reasonable to happen since contour changes are traced similarly for both methodologies. In light of this, it was additionally verified comparing with experimental data from a different measurement campaign. The ROD methodology was compared with the ID calculated using images from high-speed $\mathrm{OH}$ chemiluminescence, the processing of which has been extensively reported in the literature [33,34]. Both setups visualized the same injection event, for a total of twenty repetitions, using commercial diesel, with a rail pressure of $100 \mathrm{MPa}$, a chamber density of $19 \mathrm{~kg} \mathrm{~m}^{-3}$, and temperature of $900 \mathrm{~K}$. Despite the injected quantities were not measured, the strategy set resembled 
the pilot-main structure with an approximate dwell time of $350 \mu$ s, measured optically from the movies. The comparison results are summarized in Table 3 , and show that the ROD methodology can accurately measure ignition delays of multiple injection strategies, although validation with more experimental data could further asses the robustness of the method.

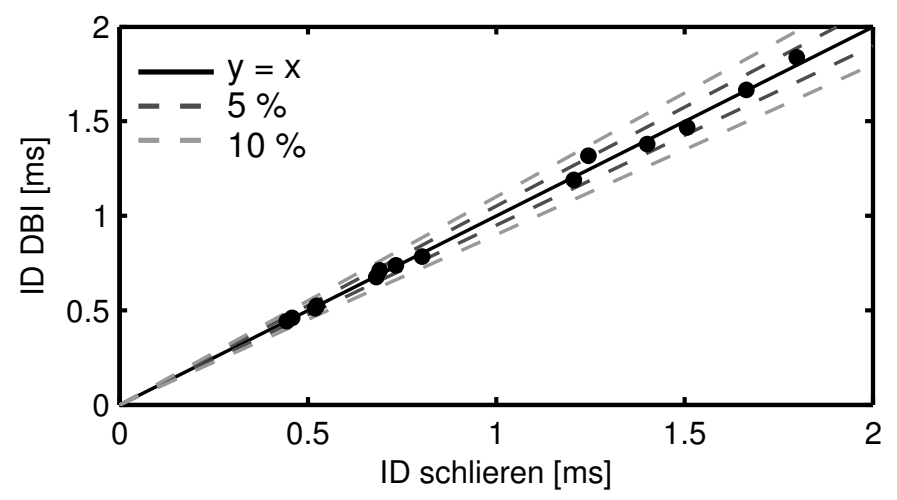

Figure 8. Correlation between ignition delays calculated with the traditional schlieren methodology and the rate of difference procedure from DBI movies for single injection cases and all boundary conditions tested.

Table 3. Comparison of the start of combustion calculated with the rate of difference and with high-speed $\mathrm{OH}$ chemiluminescence.

\begin{tabular}{cccc}
\hline Injection & ID ROD & ID OH Chem. & Units \\
\hline Pilot & $0.71 \pm 0.02$ & $0.68 \pm 0.02$ & ms after SOE \\
Main & $1.24 \pm 0.03$ & $1.23 \pm 0.08$ & ms after SOE \\
\hline
\end{tabular}

\subsection{Ignition Delay for Multiple Injection Strategies}

The ignition delay results for pilot main strategy at $800 \mathrm{~K}$ and $900 \mathrm{~K}$ are represented in Figure 9. Different symbols and colors depict the auxiliary injection quantity, always compared to the single injection case. The y-axis limits change depending on the conditions. The pilot and main ignition delay are referenced to the SOI of the pilot event to the left of the figure, and the main ID to the SOI of the main, to the right side. Further, when both pulses ignited at the same time, symbols overlap each other, and are represented by a different color. Overall, errors associated with shot-to-shot variability were under $10 \%$, decreasing to values under $5 \%$ at higher chamber temperatures and densities. This deviation shows that the injector operates under acceptable conditions. It was measured through the standard deviation of all the data gathered in [13] and was determined that the pilot/post injection was highly dependent on its transitory characteristics.

All results at $900 \mathrm{~K}$ showed the pilot pulse always igniting before the main, as the pilot ID is always shorter. The pilot ID is in accordance to the values obtained for the single injection case, with no effect on it noted from neither fuel quantity nor the main pulse, since both pilot masses have the same ID. Besides, the variation in pilot mass did not have a significant impact on the main ID. On the other hand, the main ID presented smaller values with decreasing DT probably due to less time available for products of the first combustion to cool down.

Results at $800 \mathrm{~K}$ referenced to the pilot SOI describe how the ignition delay of the pilot was affected by the main injection, as well as the opposite. For most conditions, both injections ignited simultaneously. In such cases, increasing the DT visibly lengthened the ignition delay of the pilot. Even though more time was provided for the first pulse to combust, it was caught up by the main injection in a state where it negatively influenced the ignition process [3], probably cooling down or modifying the local mixture [30,34]. On the other hand, decreasing the DT made the ID trend to values similar to the single injection, and, the specific cases where the SOC of both injections decoupled, the ID of the pilot resembled to the single. Regarding the dwell time, at $800 \mathrm{~K}$, increasing it provided more 
time for the pilot injection to mix, evaporate and combust before being caught up by the main pulse, consequently moving the ignition location upstream. On the other side, increasing the pilot quantity increased the momentum, as explained in a prior related work [14], and the pilot injection ignition kernel penetrated further into the test chamber, away from the main pulse, enabling the decoupling of the combustion of each injection pulse for DT of 500 and $650 \mu \mathrm{s}, 200 \mathrm{MPa}$ of rail pressure, and a chamber density of $22.8 \mathrm{~kg} \mathrm{~m}^{-3}$.

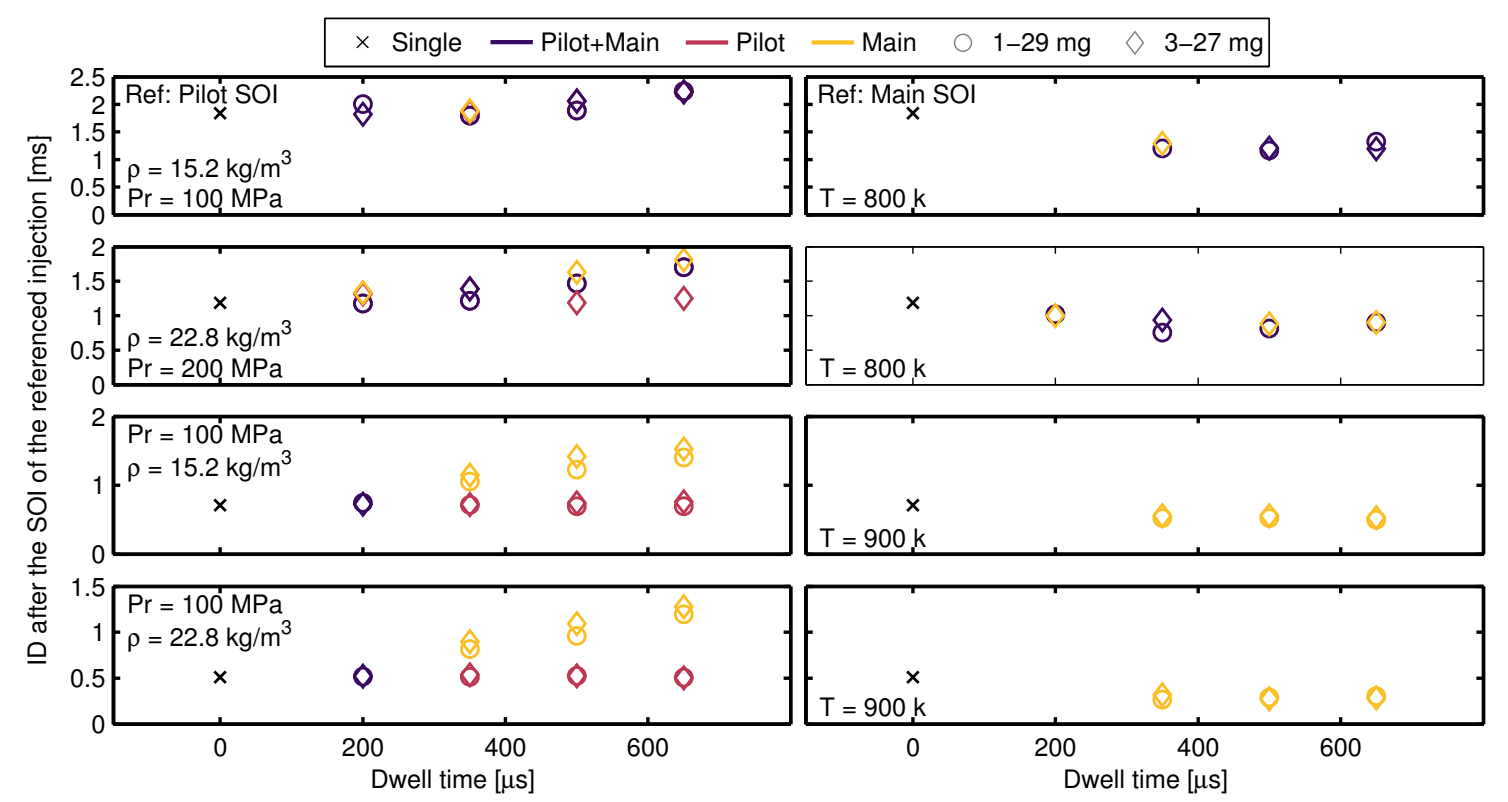

Figure 9. Ignition delay results for a pilot-main strategy chamber temperature of $800 \mathrm{~K}$ (upper two rows) and $900 \mathrm{~K}$ (lower two rows). Pilot + main refer to the cases when the pilot and main ignited simultaneously. Values are referenced to the start of injection of either the pilot (left column) or main (right column).

For all conditions, the first pulse promoted a shorter ID of the main injection from around 30\% to $40 \%$ compared to the single injection case, as observed in results to the right, which speeds up the transition from the newly injected fuel into a reacting state [35].

Ignition delay results for a main-post strategy are exposed in Figure 10. Errors associated with shot-to-shot deviation were under $10 \%$ and for higher chamber temperatures and densities under $5 \%$.

Results show that the main pulse ignites with a similar delay to the single injection, and the SOC is always decoupled for the cases showed. Overall, the ID of the post injection was shortened by the main pulse compared to the single injection case, due to the increase in chamber temperature caused by the combustion of the first pulse and re-entrainment of the hot gases [36], that also, moves the ignition location of the second pulse closer to the nozzle. This effect is more remarked for this strategy than for pilot-main, presumably owing to the longer duration of the first pulse. No effect is observed either from the post quantity or the dwell time, and probably the driving factor is the local temperature, modified by the main injection. On average, the ignition delay of the post injection referenced to its SOI was shortened from around $40 \%$ to $50 \%$ compared to its reference case. 


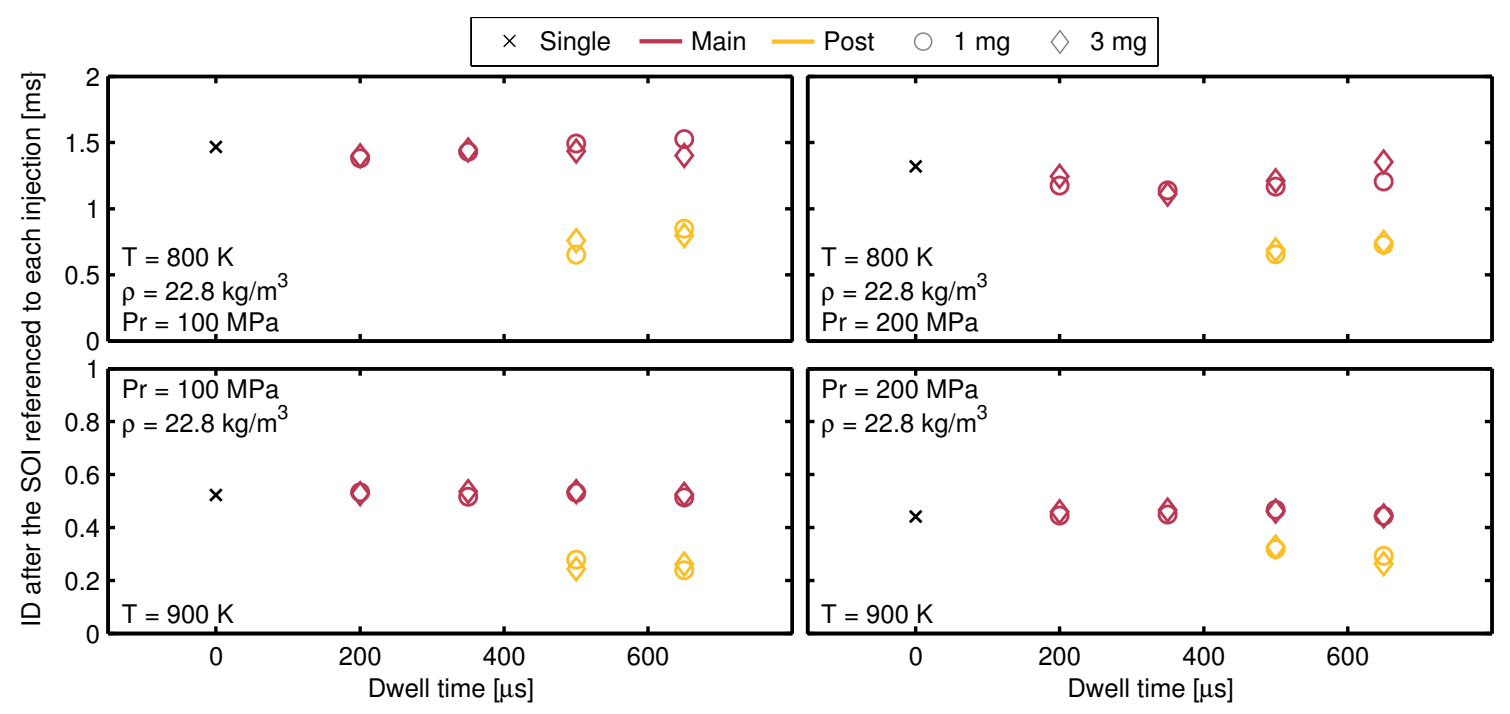

Figure 10. Ignition delay results for main-post strategies and all conditions tested. Values are referenced to the start of injection of each pulse.

To sum up the ignition delay results for all conditions tested and both strategies, they were classified in the different interaction mechanisms that summarize the effects of the first pulse on the second event. Classification adapted from the definition given by Jorques Moreno et al. [37] for the effects of a pilot injection on the main.

1. Mixing interaction mode: when the second injection takes place during the mixing phase of the first pulse. It was seen only for pilot-main strategies, mostly at the lowest chamber density and/or temperature, and for some intermediate conditions where the pilot did not ignite before the main caught up. The SOC of the main pulse is driven by the ignition of the pilot.

2. Premixed interaction mode: the second injection takes place during the premixed combustion of the first pulse and independent combustion events for each injection are visualized. This was observed for most points in the pilot-main strategy at the highest chamber density and/or temperature, and also for combinations of either low chamber temperature and high density, or vice versa. The reach of the trade-off between the premixed and diffusive combustion is dependent on the boundary conditions and also on the DT and pilot quantity, as they determine the temperature of the local gases entrained by the main injection.

3. Diffusive interaction mode: the second injection befalls during the diffusive combustion of the first pulse. It was observed for all conditions in main-post strategies due to the time allowed between the SOC of the main injection and the relatively short DT to the post-pulse. It was also noted for some of the $3 \mathrm{mg}$ pilots at higher chamber temperature and density, and low rail pressure.

4. Completed combustion interaction mode: the second injection occurs after the combustion of the first pulse is completed. This interaction mode did not appear for the conditions studied because of the short dwell times used in this investigation.

The results showed that the transition between interaction modes can be controlled by both the injected quantity and dwell time. Decreasing the last, shifted their interaction to a mixing mode as the pilot did not have enough time to ignite before being caught up by the main pulse. Contrarily, increasing the pilot quantity by a sufficient amount, and with a short dwell time, a diffusive interaction mode might be achieved.

\subsection{Ignition Location}

The approximate ignition location results are presented for all conditions tested in which ignition occurred within the field of view $(50 \mathrm{~mm})$, and are exposed in Figure 11, showing a similar trend as 
the ignition delay [36]. This parameter was estimated in order to provide a reference of how a pilot injection might have affected the lift-off length of the main pulse, since it is a determinant factor on the soot formation, due to depending on whether the combustion occurs closer to the nozzle, more soot is expected to form and combustion takes place in richer conditions [7]. The technique normally used to quantify this characteristic is $\mathrm{OH}$ chemiluminescence, nevertheless, for the current study it was no possible to properly realize, given that no high speed intensifier was available. Some measurements were done with an intensified charge-coupled device (ICCD) camera equipped with a $100 \mathrm{~mm} f / 2.9$ UV-capable lens to capture the low-intensity signal from the combustion, which was only able to obtain an averaged image per condition, thus, it was gathered for the specific times of the stabilized period in the combustion. Nonetheless, no clear trend was found regarding the effects of both DT and pilot quantity. It is important to remark that, $\mathrm{LOL}$ is a transitory variable along the injection event that can change from the inception of combustion until an established diffusion flame [33], and that might not be visible from a time-averaged frame. Also, reducing the exposure of the camera to focus the LOL near the SOC of the main injection created very irregular contours that were difficult to process and showed high shot-to-shot variability.

Based on the above, a methodology to estimate the location of the ignition was developed using the ID, being that the ignition location related to the ignition delay is a determinant factor in the lift-off length [38]. It was calculated with the centroid of the local maximum rate of difference at the time corresponding to the SOC. The results are approximate because the ignition kernels did not present uniform shapes, but a high shot-to-shot variability, for this reason, the values shown are only for qualitative representation.
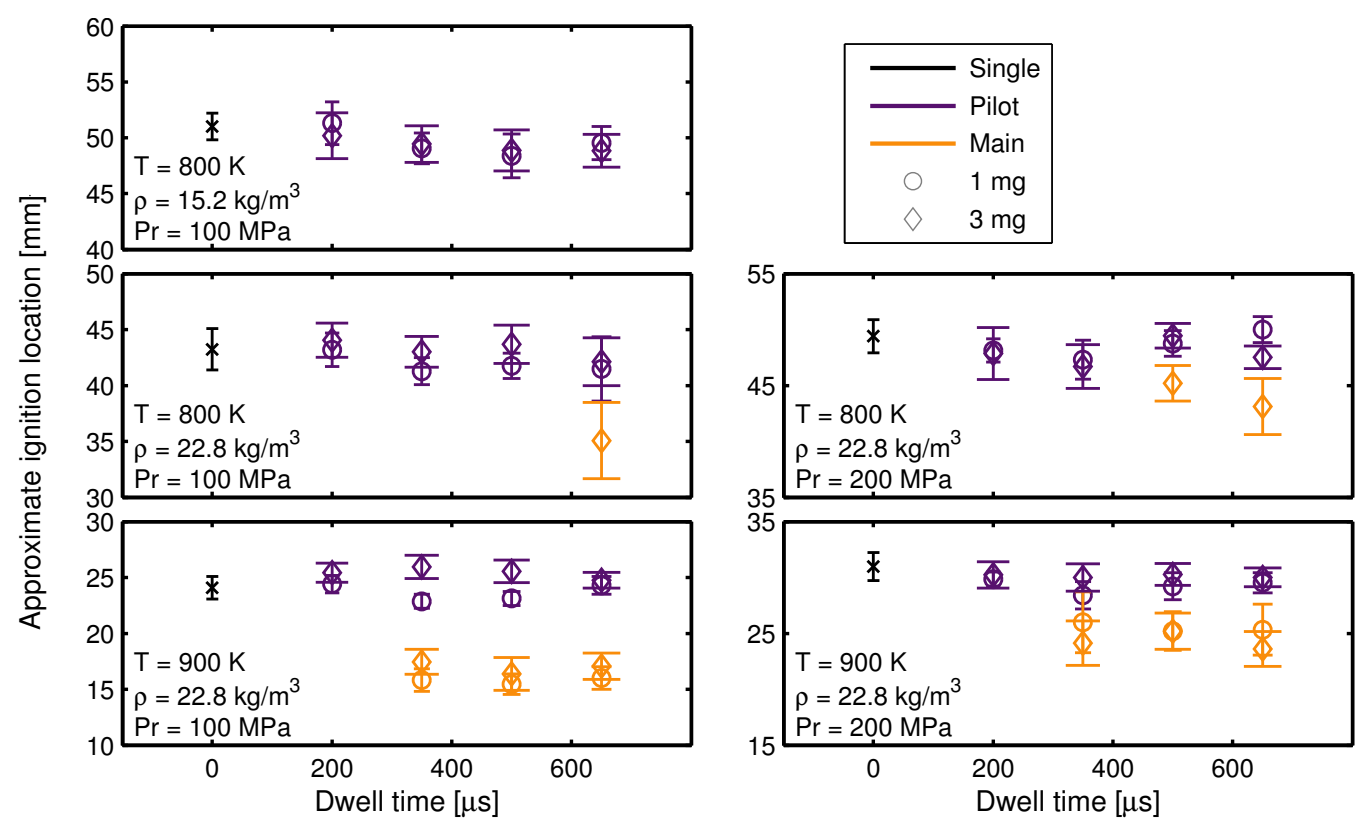

Figure 11. Ignition location results for pilot-main strategies and all conditions in which ignition occurred within the field of view. Error-bars represent shot-to-shot dispersion, depicting a different cap size for the $3 \mathrm{mg}$ (wider) and $1 \mathrm{mg}$ (narrower) pilots.

Results show that the ignition location is dependent on the interaction mode between pulses, as claimed by other authors [3,33,36], either acting as a single injection in a mixing interaction mode, or as two different combustion events that interact with each other. For a single injection, the first ignition kernels typically occur in richer mixtures near the spray head, propagating on one side towards the spray tip, and on the other towards the nozzle up to the lift-off region. From this, and according to the literature, a shorter lift off length is expected for the main pulse in the beginning and then, a slowly 
shift towards equilibrium of the stabilized flame, owing that pilot injections accelerate the vaporization process and reaction rate of the main $[33,37]$.

\subsection{Soot Distribution for Multiple Injections}

The results are presented in terms of the optical thickness $(K L)$ of the flame soot from the methodology explained in Section 2.4.1. Soot maps were constructed to depict flame evolution throughout the injection event, assuming flame symmetry. The cross-sectional KL is represented by a color scale divided in two ranges depending on the soot formation level of each case. The y-axis represents the axial distance, so it is possible to see the position where the soot is formed.

\subsubsection{Effect of Boundary Conditions in Soot Distribution}

The effect of rail pressure, chamber density and temperature for single injections as reference are collected in the Figure 12. This clearly shows how increasing the rail pressure drastically reduces the cross-sectional KL, and moves the ignition location downstream of the nozzle, thus, initial combustion and diffusion flame occur in leaner conditions, less ideal for forming soot [7]. Contrarily, with higher chamber density the cross-sectional KL increments, and shifts the sooting region closer to the nozzle. For this condition, it is important to consider that several variables affecting soot production are influenced by the density, hence, the trend described may be dependent of more complex interactions. For example, Pickett and Siebers [39] explained the shift in the soot region as a result of two variables: a decrease in the lift-off length and the increase in the overall air entrained relative to the amount of fuel injected. On the other hand, with regard to the chamber temperature, increasing it, soot formation rises, and turns the sooting region close to the nozzle. Both the ignition delay and lift-off length decrease at higher chamber temperature [8-10], increasing the local equivalence ratio at the lift-off location, hence, soot starts forming in richer conditions. Note how at $800 \mathrm{~K}$, almost no soot is observed, even at the lowest rail pressure and highest chamber density.

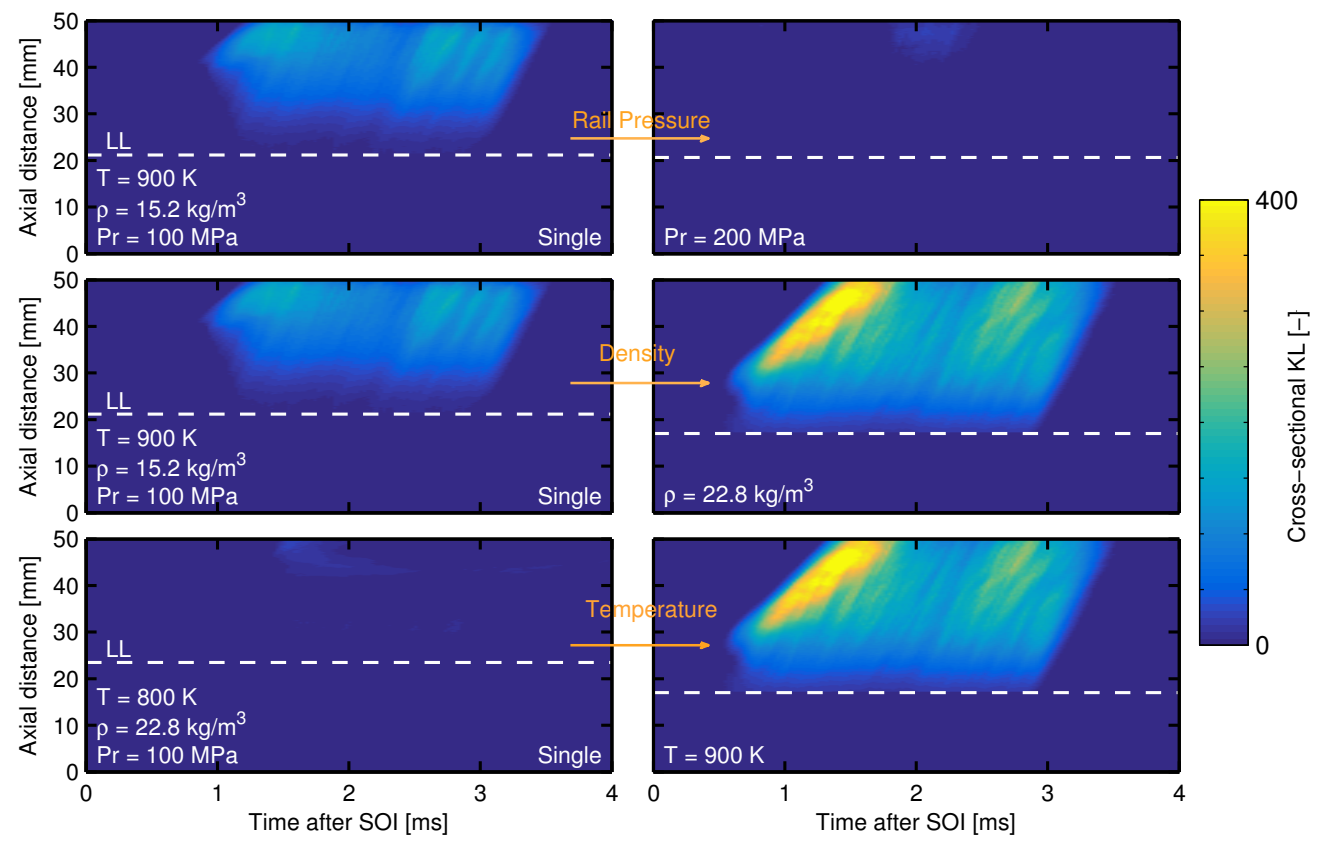

Figure 12. Effect of the rail pressure, chamber density, and chamber temperature, divided row-wise respectively, on the evolution of the cross-sectional optical thickness (KL) at each axial distance for single injection events. The dashed white line represents the liquid length for each specific condition and the orange arrows represent the direction of the variable changed. 


\subsubsection{Soot Distribution for Pilot-Main Strategies}

For this analysis, Figures 13 and 14 are shown in order to see the differences between a condition with high soot formation and the other with low. The soot maps are organized row-wise by dwell time, and column-wise by pilot quantities, and they have the mass flow pulses plotted in order to see when the pulses are injected.
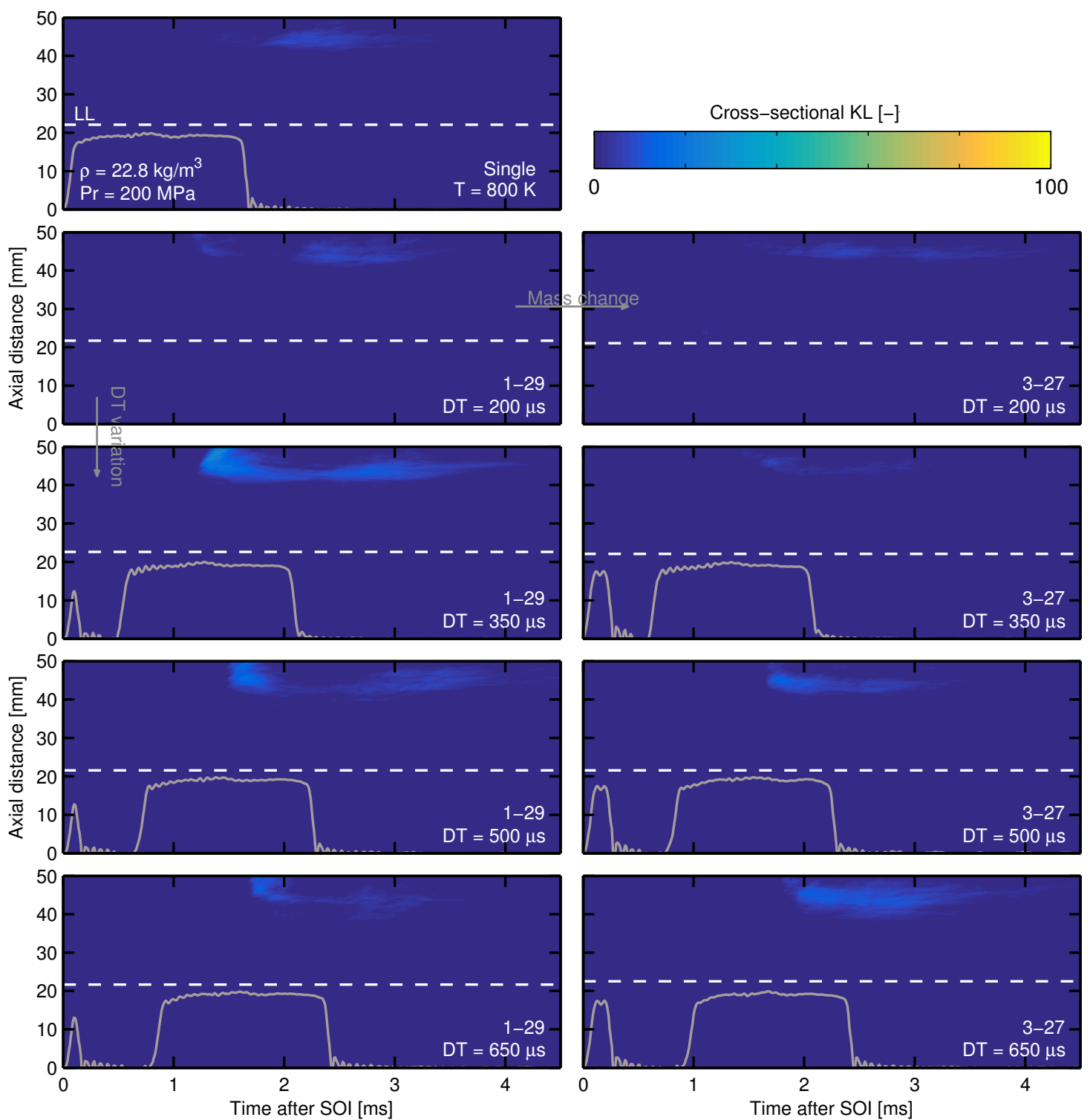

Figure 13. Evolution of the cross-sectional $\mathrm{KL}$ at each axial distance for pilot-main strategies, for a rail pressure of $200 \mathrm{MPa}$, a chamber density of $22.8 \mathrm{~kg} \cdot \mathrm{m}^{-3}$ and temperature of $800 \mathrm{~K}$. The dashed white lines depict the liquid length. The mass flow pulses [13] are plotted when they decoupled. Gray arrows represent the direction of the variable changed for comparison. 

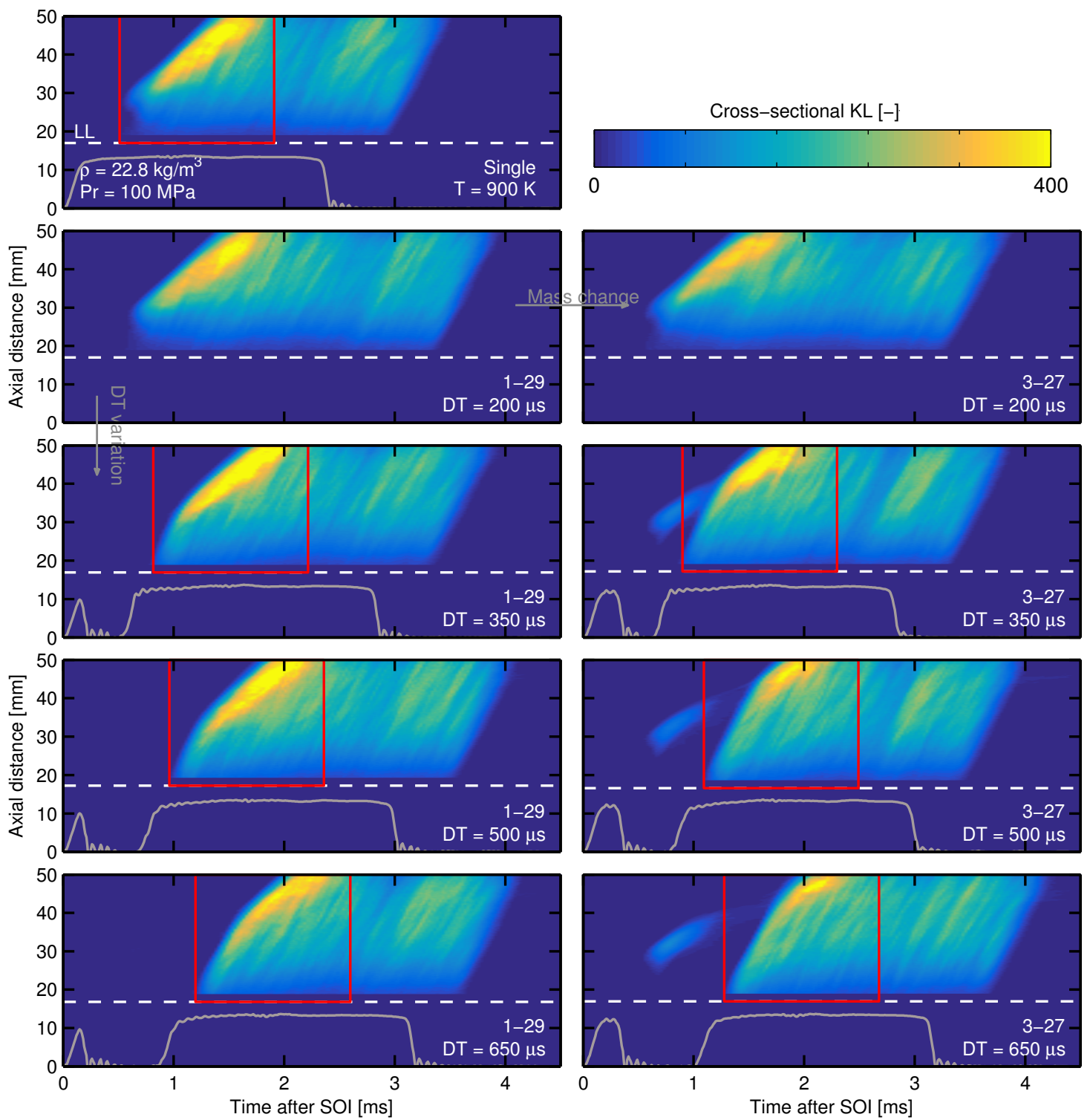

Figure 14. Evolution of the cross-sectional $\mathrm{KL}$ at each axial distance for pilot-main strategies for a rail pressure of $100 \mathrm{MPa}$, a chamber density of $22.8 \mathrm{~kg} \cdot \mathrm{m}^{-3}$ and temperature of $900 \mathrm{~K}$. The dashed white lines depict the liquid length. Red dashed rectangle represent a reference for the Table 4 of the first $1.4 \mathrm{~ms}$ after the SOC of the main for dwell times of $350 \mu \mathrm{s}$ and the single injection. The mass flow pulses [13] are plotted when they decoupled. Gray arrows represent the direction of the variable changed for comparison.

It was observed that this strategy produces more soot than a single injection, as trends introduced by several authors $[34,36]$ who studied the impact of a pilot injection on the ignition processes from some measurements in single-cylinder optical diesel engine. In general, the $1 \mathrm{mg}$ pilots combusted and stagnated closer to the nozzle, promoting a higher soot production of the main injection. This is presumably due to the main pulse burning with a higher equivalence ratio, ideal for soot formation, although this observation might be limited to the field of view used. Contrarily, the $3 \mathrm{mg}$ pilot ignition kernel moved farther downstream of the nozzle, and the main injection reached the pilot kernel probably in leaner conditions producing lower soot quantities, as similar trends remarked by [3]. An illustration of this case is depicted in Figure 15, which show that the $1 \mathrm{mg}$ pilot ignition occurs closer to the nozzle, in consequence, its main injection will interact earlier with the remnant fuel of the pilot. Besides, it was observed that the $3 \mathrm{mg}$ pilot injection briefly established as a diffusion flame. 

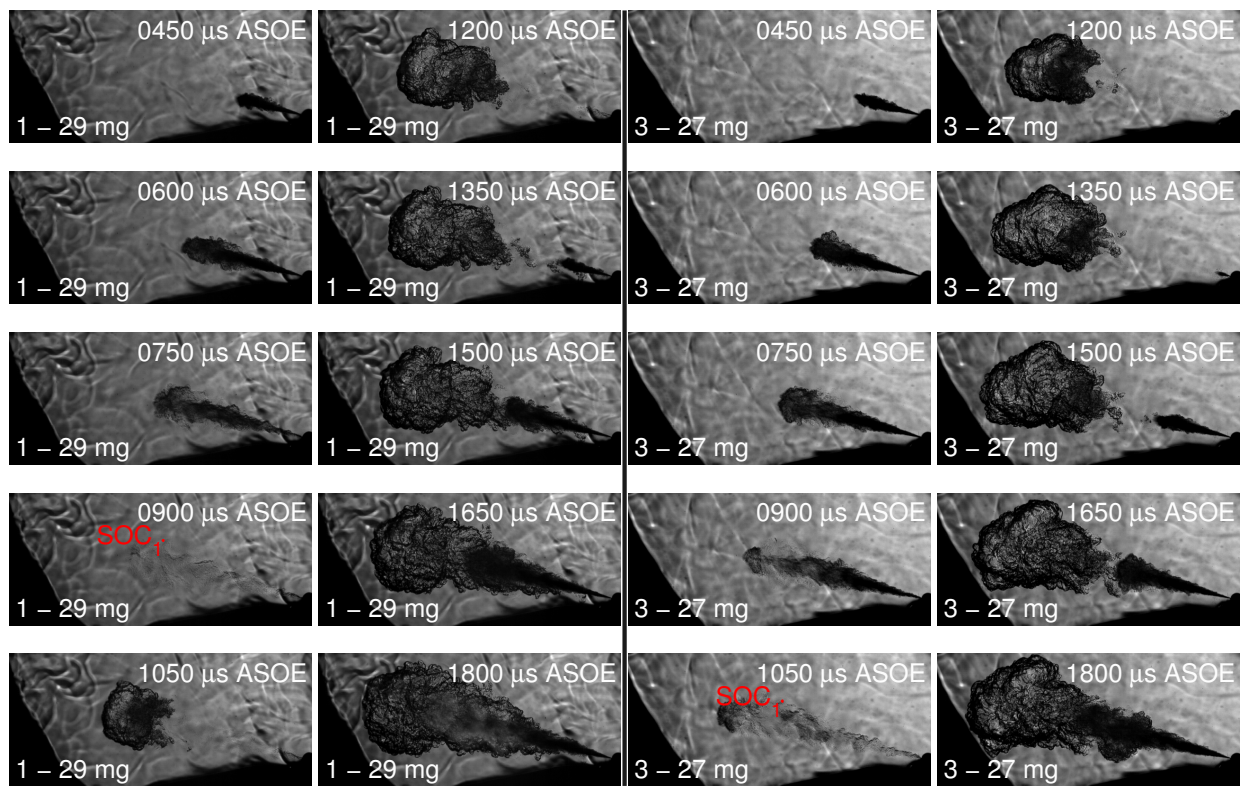

Figure 15. Sequence of schlieren images of a pilot injection of $1 \mathrm{mg}$ and other of $3 \mathrm{mg}$. The images show the ignition of the first pulse for each mass quantity before the second pulse. The frames are referenced to the start of energizing (SOE). The conditions are $900 \mathrm{~K}$ of chamber temperature, a rail pressure of $100 \mathrm{MPa}$, chamber density of $15.2 \mathrm{~kg} \cdot \mathrm{m}^{-3}$, and a dwell time of $650 \mu \mathrm{s}$.

The increase in soot formation with the inclusion of a pilot injection can be explained by several factors. For instance, qualitative ignition location results showed that the lift-off length of the main injection should start closer upstream from the nozzle, resulting in less air entrainment, and accordingly, more soot being the strong link between soot and the air entrained upstream of the lift-off length underlined by Siebers and Higgins [7] and Payri et al. [16], who claimed that higher air entrainment is likely to result in less soot production, and contrarily when non-vaporized fuel penetrates beyond the flame lift-off length. Although these studies were performed with a single injection, the same approach can be used for multiple injections. Having said that, it makes sense that the increase of soot production is more noticeable at higher chamber densities and temperatures as it is remarked in the differences between Figures 13 and 14, given that the ignition location of the main event decreases, as well as the ID, and its combustion occurs in temperature and mixture conditions that promote the appearance of soot earlier in the injection event, as has been extensively reported $[7,36]$, also confirming that the chamber conditions govern the interaction between pulses.

No clear trend on the dependence of soot on the dwell time is seen, however, for a fixed boundary condition and pilot quantity, differences in the cross-sectional $\mathrm{KL}$ are depicted in the figures while varying the pulse separation.

One interesting fact that can be appreciated from Figure 14 and it is resumed in Table 4 is the higher soot formation in the early stages of the multiple injections strategies (when they decoupled), compared to the reference case, which reassure the negative influence of the pilot injection. From the table it is also possible to see a decreasing in the soot formation with increasing the mass, but, it is important to bear in mind that these values are dependent on the field of view, and the trend observed for the DT and mass pulses is probably due to the soot forming out of this field, given the further penetration of the ignition kernel previously discussed for those cases.

Additionally, for pilots of $3 \mathrm{mg}$ for both rail pressures and a chamber density of $22.8 \mathrm{~kg} \cdot \mathrm{m}^{-3}$ and temperature of $900 \mathrm{~K}$ presented soot production. In such cases, the pulse was long enough allowing chamber conditions to establish a brief diffusion flame, and corroborating that the main injection interacts with the pilot in a diffusive mode. Finally, for the lowest chamber density and temperature no soot formation was observed for both rail pressures. 
Table 4. Summary of KL sum in the first stages for pilot-main strategies for a rail pressure of $100 \mathrm{MPa}$, a chamber density of $22.8 \mathrm{~kg} \cdot \mathrm{m}^{-3}$ and temperature of $900 \mathrm{~K}$ and $800 \mathrm{~K}$ when pulses decoupled. The mass flow pulses [13] are plotted.

\begin{tabular}{ccccc}
\hline KL Sum $\times \mathbf{1 0}^{\mathbf{6}}$ & Ref & $\mathbf{1 - 2 9}$ & $\mathbf{3 - 2 7}$ & $\mathbf{T} \mathbf{( K )}$ \\
\hline $\mathrm{DT}=350$ & 0.0366 & 0.1512 & 0.0795 & 800 \\
$\mathrm{DT}=500$ & 0.0366 & 0.1670 & 0.0874 & 800 \\
$\mathrm{DT}=650$ & 0.0366 & 0.2351 & 0.0907 & 800 \\
$\mathrm{DT}=350$ & 2.09 & 2.37 & 2.46 & 900 \\
$\mathrm{DT}=500$ & 2.09 & 2.37 & 2.34 & 900 \\
$\mathrm{DT}=650$ & 2.09 & 2.23 & 2.29 & 900 \\
\hline
\end{tabular}

\subsubsection{Soot Distribution for Main-Post Strategies}

The same plots presented for pilot-post strategies were done for main-post strategies (but row-wise divided by dwell time and post quantity, and column-wise by rail pressure). Nonetheless, in this strategy, soot maps are not displayed for DT of $200 \mu \mathrm{s}$ and $350 \mu \mathrm{s}$, as well as for the lowest chamber density and temperature, since pulses did not decouple and no soot formation was observed.

Despite the fact that it is widely known that post injections are useful for the reduction of soot exhaust emissions [11,40], the results obtained show that soot formation increases slightly, or it is at least equal, with the inclusion of a post injection compared to the reference case. Moreover, specifically as seen in Figure 16, decreasing the DT and increasing the post quantity notably promoted soot production.
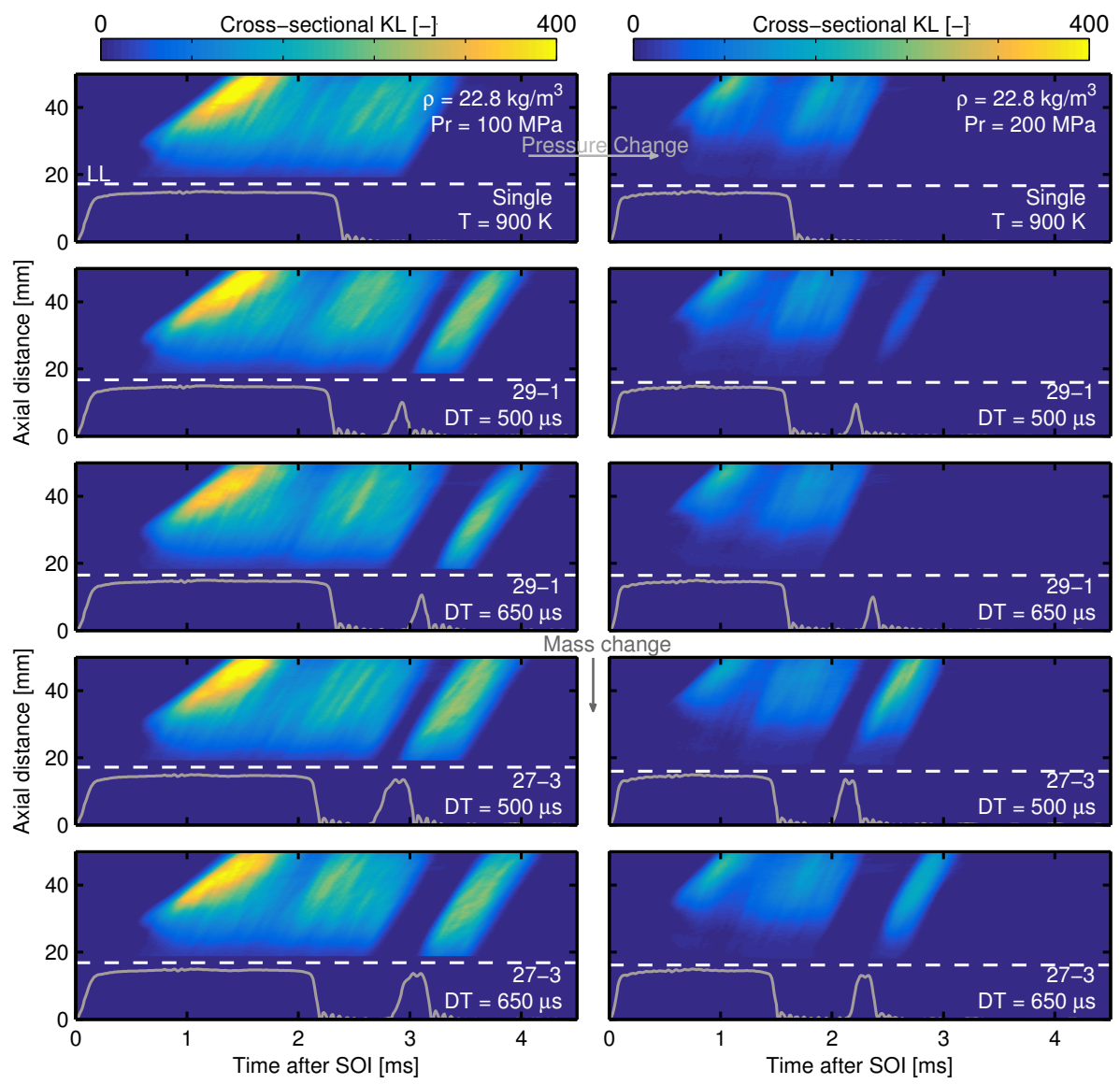

Figure 16. Evolution of the cross-sectional $\mathrm{KL}$ at each axial distance for main-post strategies, for a rail pressure of $100 \mathrm{MPa}$ (left) and $200 \mathrm{MPa}$ (right), a chamber density of $22.8 \mathrm{~kg} \cdot \mathrm{m}^{-3}$, and temperature of $900 \mathrm{~K}$. The dashed white lines depict the liquid length of the main (horizontal), and start of injection of the post (vertical). Gray arrows represent the direction of the variable changed for comparison. 
O'Connor and Musculus [5] provided a very detailed literature review of the processes involved in soot formation and oxidation with a post injection, with multiple references of both experimental and modeling data from optical and real engines. In general, some of the interactions highlighted the importance of a confined cylinder bowl to increase mixing and enhance the targeting by the post pulse of the main injection residual mixture. Consequently, the effectiveness of the post injection on reducing soot emissions is closely linked to a restrained engine bowl-shaped combustion chamber. As a matter of fact, Payri et al. [41] and Zhao et al. [42] concluded that spray-wall interactions enhance soot oxidation due to higher mixing with ambient air caused by wall impingement. Further, they found that the heat exchanged with the walls cooled down the jet, slowing the rate of soot formation.

From this principle, one reason for the results attained is that the type of combustion chamber used for the measurements provide a large volume for the spray to develop, and the post injection behaves like a main and the actual main like a pilot. Thence, after the combustion recession of the main pulse, local conditions enhance the soot formation from the post injection, instead of its oxidation. Thus, to accurately quantify the effects of post injections, similar geometries that emulate these mechanisms must be tested.

\section{Conclusions}

The results of several measurements of multi-injection parameters and how they influence the combustion in diesel engines were analyzed. The strategies were simplified by studying the interaction between pilot-main, and main-post pulses. To this aim, measurements were carried out with a combination of optical techniques: diffused back-illumination with flame radiation to quantify soot, synchronized with single-pass schlieren for ignition delay. The field of view allowed an optical limit of approximately $50 \mathrm{~mm}$.

- A novel image processing methodology based on the absolute pixel-wise frame-to-frame difference was developed to decouple the start of combustion of each spray in multiple injection strategies. The methodology was successfully validated against a different experimental campaign results, although validation with more experimental data is recommended.

- For all test points, the pilot injection enhanced conditions that promote a faster ignition of the main pulse. Increasing the dwell time promoted higher ID for the pilot injection. On the contrary, increasing the pilot quantity provided a higher momentum, which increased the ID of the pilot. On average, the ignition delay of the main pulse was reduced around $30 \%$ to $40 \%$ compared to its single injection case.

- At lower chamber temperatures, the pilot and main pulses ignited simultaneously, and increasing the dwell time negatively influenced the ignition process. On the contrary, at higher temperatures, all conditions presented a separate combustion event for each injection, with no effect from neither the pilot quantity nor the dwell time on the main. Ignition delay values seemed to decrease slightly when lowering dwell time, and no clear trend was observed for pilot quantities.

- For the main-post strategy, all conditions manifested a separate combustion event for each injection. In fact, higher localized temperature promoted an even faster ignition of the second pulse compared to pilot-main strategies. Overall, the ID of the post injection was reduced around $40 \%$ to $50 \%$ compared to its reference case.

- From soot measurements, boundary conditions affected soot formation in single injections as expected from literature. On the other hand, for pilot-main strategies, more soot was observed compared to its reference case. Overall, it was observed that conditions that promote faster premixed combustion enhance soot formation, as most of the fuel is burned in a diffusion flame. In this context, when increasing the pilot quantity a diminution in the cross-sectional KL near the SOC was observed, and no clear trend of the dependence of soot on the dwell time was observed, although, for fixed boundary conditions differences are noticed. 
- In contrast to what is reported in the literature, main-post strategies depicted slightly higher or similar soot formation than a single injection. The reason for it is that for this type of large volume vessels, the post injection behaves like a main and the actual main like a pilot, and there is no re-circulation of the combustion products. In this sense, different experimental works also showed that the soot oxidation processes are very dependent on the interaction between the injections and the confined engine bowl-shaped combustion chamber.

Author Contributions: R.P. supervised the measurements and the writing of the article. J.M.G.-O. reviewed the manuscript and contributed to the combustion analysis. V.M. did the writing and some experimental analysis. A.V. performed the investigations, experiments, and analysis of the data. All authors read the manuscript and contributed to the discussion. All authors have read and agreed to the published version of the manuscript.

Funding: This research has been partially funded by Spanish "Ministerio de Ciencia, Innovación y Universidades" through project RTI2018-099706-B-100. Additionally, the experimental hardware was purchased through FEDER and Generalitat Valenciana under project IDIFEDER/2018/037.

Acknowledgments: The authors thank to the laboratory technician Omar Huerta for his invaluable help along the acquisition of the experimental data.

Conflicts of Interest: The authors declare no conflict of interest.

\section{Abbreviations}

The following abbreviations are used in this manuscript:

$\begin{array}{ll}\text { DBI } & \text { Diffused back-illumination } \\ \text { ECN } & \text { Engine Combustion Network } \\ \text { ECU } & \text { Engine Control Unit } \\ \text { EOI } & \text { End of injection } \\ \text { ID } & \text { Ignition delay } \\ \text { LED } & \text { Light-emitting diode } \\ \text { LOL } & \text { Lift-off length } \\ \text { ROD } & \text { Rate of difference } \\ \text { ROI } & \text { Rate of injection } \\ \text { SOC } & \text { Start of combustion } \\ \text { SOE } & \text { Start of energizing } \\ \text { SOI } & \text { Start of injection } \\ \text { DT } & \text { Dwell time } \\ \text { PCR } & \text { Piezo common-rail }\end{array}$

\section{References}

1. Musculus, M.P.B.; Miles, P.C.; Pickett, L.M. Conceptual models for partially premixed low-temperature diesel combustion. Prog. Energy Combust. Sci. 2013, 39, 246-283. [CrossRef]

2. Han, S.; Kim, J.; Bae, C. Effect of air-fuel mixing quality on characteristics of conventional and low temperature diesel combustion. Appl. Energy 2014, 119, 454-466. [CrossRef]

3. Mingfa, Y.; Hu, W.; Zunqing, Z.; Yan, Y. Experimental Study of Multiple Injections and Coupling Effects of Multi-Injection and EGR in a HD Diesel Engine; SAE Technical Paper 2009-01-2807; SAE International: Warrendale, PA, USA, 2009. [CrossRef]

4. Schöppe, D.; Stahl, C.; Krüger, G.; Dian, V. Servo-Driven Piezo Common Rail Diesel Injection System. ATZ Autotechnol. 2012, 12, 42-47. [CrossRef]

5. O'Connor, J.; Musculus, M.P.B. Post Injections for Soot Reduction in Diesel Engines: A Review of Current Understanding. SAE Int. J. Engines 2013, 6. [CrossRef]

6. Samuel, J.J. A physics-based model for real-time prediction of ignition delays of multi-pulse fuel injections in direct-injection diesel engines. Int. J. Engine Res. 2020, 21, 540-558. [CrossRef]

7. Siebers, D.L.; Higgins, B.S. Flame Lift-Off on Direct-Injection Diesel Sprays Under Quiescent Conditions; SAE Technical Paper 2001-01-0530; SAE International: Warrendale, PA, USA, 2001. [CrossRef]

8. Benajes, J.; Payri, R.; Bardi, M.; Martí-Aldaraví, P. Experimental characterization of diesel ignition and lift-off length using a single-hole ECN injector. Appl. Therm. Eng. 2013, 58, 554-563. [CrossRef] 
9. Payri, R.; Salvador, F.J.; Manin, J.; Viera, A. Diesel ignition delay and lift-off length through different methodologies using a multi-hole injector. Appl. Energy 2016, 162, 541-550. [CrossRef]

10. Higgins, B.S.; Siebers, D.L.; Aradi, A. Diesel-Spray Ignition and Premixed-Burn Behavior; SAE Technical Paper 2000-01-0940; SAE International: Warrendale, PA, USA, 2000. [CrossRef]

11. O'Connor, J.; Musculus, M.P.B. Effects of exhaust gas recirculation and load on soot in a heavy-duty optical diesel engine with close-coupled post injections for high-efficiency combustion phasing. Int. J. Engine Res. 2014, 15, 421-443. [CrossRef]

12. Baert, R.S.G.; Frijters, P.J.M.; Somers, B.; Luijten, C.C.M.; Boer, W.D.; De Boer, W. Design and Operation of a High Pressure, High Temperature Cell for HD Diesel Spray Diagnostics: Guidelines and Results; SAE Technical Paper 2009-01-0649; SAE International: Warrendale, PA, USA, 2009. [CrossRef]

13. Payri, R.; Gimeno, J.; Martí-Aldaraví, P.; Viera, A. Measurements of the mass allocation for multiple injection strategies using the rate of injection and momentum flux signals. Int. J. Engine Res. 2020. [CrossRef]

14. Payri, R.; Salvador, F.J.; Abboud, R.; Viera, A. Study of evaporative Diesel spray interaction in multiple injections using optical diagnostics. Appl. Therm. Eng. 2020, 176, 115402. [CrossRef]

15. Payri, R.; Salvador, F.J.; Gimeno, J.; Viera, A. Effect of Injection Rate Shaping over Diesel Spray Development in Non-Reacting Evaporative Conditions. In Tagung Diesel- und Benzindirekteinspritzung 2016; Tschöke, H., Marohn, R., Eds.; Springer: Berlin/Heidelberg, Germany, 2017; Number 1, pp. 133-152. [CrossRef]

16. Payri, R.; Bracho, G.; Martí-Aldaraví, P.; Viera, A. Nozzle Geometry Size Influence on Reactive Spray Development: From Spray B to Heavy Duty Applications; SAE Technical Paper 2017-01-0846; SAE International: Warrendale, PA, USA, 2017; p. 12. [CrossRef]

17. Payri, R.; Gimeno, J.; Cardona, S.; Ayyapureddi, S. Experimental study of the influence of the fuel and boundary conditions over the soot formation in multi-hole diesel injectors using high-speed color diffused back-illumination technique. Appl. Therm. Eng. 2019, 158, 113746. [CrossRef]

18. Meijer, M.; Somers, B.; Johnson, J.E.; Naber, J.D.; Lee, S.Y.; Malbec, L.M.; Bruneaux, G.; Pickett, L.M.; Bardi, M.; Payri, R.; et al. Engine Combustion Network (ECN): Characterization and Comparison of Boundary Conditions for Different Combustion Vessels. At. Sprays 2012, 22, 777-806. [CrossRef]

19. Engine Combustion Network. 2010. Available online: https://ecn.sandia.gov/diesel-spray-combustion/ (accessed on 20 September 2018).

20. Ghandhi, J.B.; Heim, D.M. An optimized optical system for backlit imaging. Rev. Sci. Instruments 2009, 80, 056105. [CrossRef] [PubMed]

21. Settles, G.S. Shadowgraph and Schlieren Techniques; Springer: Berlin/Heidelberg, Germany, 2001. [CrossRef]

22. Meijer, M.; Malbec, L.M.; Bruneaux, G.; Somers, B. Engine Combustion Network: Spray A Basic Measurements and Advanced Diagnostics. In Proceedings of the ICLASS 12th Triennial International Conference on Liquid Atomization and Spray Systems, Heidelberg, Germany, 2-6 September 2012.

23. Vaquerizo, D. Study on Advanced Spray-Guided Gasoline Direct Injection Systems. Ph.D. Thesis, Universitat Politècnica de València, Valencia, Spain, 2017.

24. Viera, A. Effect of Multiple Injection Strategies on the Diesel Spray Formation and Combustion Using Optical Diagnostics. Ph.D. Thesis, Universitat Politécnica de Valéncia, Valencia, Spain, 2019.

25. Manin, J.; Bardi, M.; Pickett, L.M. Evaluation of the liquid length via diffused back-illumination imaging in vaporizing diesel sprays. In Proceedings of the International Symposium on Diagnostics and Modeling of Combustion in Internal Combustion Engines, Fukuoka, Japan, 23-26 July, 2012; Volume 8, pp. 665-673. [CrossRef]

26. Payri, R.; Salvador, F.J.; Bracho, G.; Viera, A. Differences between single and double-pass schlieren imaging on diesel vapor spray characteristics. Appl. Therm. Eng. 2017, 125, 220-231. [CrossRef]

27. Payri, R.; Gimeno, J.; Bracho, G.; Vaquerizo, D. Study of liquid and vapor phase behavior on Diesel sprays for heavy duty engine nozzles. Appl. Therm. Eng. 2016, 107, 365-378. [CrossRef]

28. Pastor, J.V.; Payri, R.; García-Oliver, J.M.; Nerva, J.G. Schlieren Measurements of the ECN-Spray A Penetration under Inert and Reacting Conditions; SAE Technical Paper 2012-01-0456; SAE International: Warrendale, PA, USA, 2012. [CrossRef]

29. Siebers, D.L. Liquid-Phase Fuel Penetration in Diesel Sprays; SAE Technical Paper 980809; SAE International: Warrendale, PA, USA, 1998. [CrossRef] 
30. Skeen, S.A.; Manin, J.; Pickett, L.M.; Cenker, E.; Bruneaux, G.; Kondo, K.; Aizawa, T.; Westlye, F.R.; Dalen, K.; Ivarsson, A.; et al. A Progress Review on Soot Experiments and Modeling in the Engine Combustion Network (ECN). SAE Int. J. Engines 2016, 9. [CrossRef]

31. Payri, R.; García-Oliver, J.M.; Xuan, T.; Bardi, M. A study on diesel spray tip penetration and radial expansion under reacting conditions. Appl. Therm. Eng. 2015, 90, 619-629. [CrossRef]

32. Wu, G.; Zhou, X.; Li, T. Temporal Evolution of Split-Injected Fuel Spray at Elevated Chamber Pressures. Energies 2019, 12, 4284. [CrossRef]

33. Maes, N.; Bakker, P.C.; Dam, N.; Somers, B. Transient Flame Development in a Constant-Volume Vessel Using a Split-Scheme Injection Strategy. SAE Int. J. Fuels Lubr. 2017, 10. [CrossRef]

34. Park, C.; Busch, S. The influence of pilot injection on high-temperature ignition processes and early flame structure in a high-speed direct injection diesel engine. Int. J. Engine Res. 2018, 19, 668-681. [CrossRef]

35. Kozlov, A.; Grinev, V.; Terenchenko, A.; Kornilov, G. An Investigation of the Effect of Fuel Supply Parameters on Combustion Process of the Heavy-Duty Dual-Fuel Diesel Ignited Gas Engine. Energies 2019, 12, 2280. [CrossRef]

36. Desantes, J.M.; García-Oliver, J.M.; García, A.; Xuan, T. Optical study on characteristics of non-reacting and reacting diesel spray with different strategies of split injection. Int. J. Engine Res. 2018, 20, 606-623. [CrossRef]

37. Jorques Moreno, C.; Stenlaas, O.; Tunestal, P. Influence of Small Pilot on Main Injection in a Heavy-Duty Diesel Engine; SAE Technical Paper 2017-01-0708; SAE International: Warrendale, PA, USA, 2017. [CrossRef]

38. Ameen, M.M.; Abraham, J. RANS and LES Study of Lift-Off Physics in Reacting Diesel Jets; SAE Technical Paper 2014-01-1118; SAE International: Warrendale, PA, USA, 2014. [CrossRef]

39. Pickett, L.M.; Siebers, D.L. Soot in diesel fuel jets: Effects of ambient temperature, ambient density, and injection pressure. Combust. Flame 2004, 138, 114-135. [CrossRef]

40. Wu, T.; Yao, A.; Yao, C.; Pan, W.; Wei, H.; Chen, C.; Gao, J. Effect of diesel late-injection on combustion and emissions characteristics of diesel/methanol dual fuel engine. Fuel 2018, 233, 317-327. [CrossRef]

41. Payri, R.; Gimeno, J.; Peraza, J.E.; Bazyn, T. Spray/wall interaction analysis on an ECN single-hole injector at diesel-like conditions through Schlieren visualization. In Proceedings of the ILASS Europe 28th Conference on Liquid Atomization and Spray Systems, Valencia, Spain, 6-8 September 2017; pp. 200-207. [CrossRef]

42. Zhao, L.; Torelli, R.; Zhu, X.; Naber, J.D.; Lee, S.Y.; Som, S.; Scarcelli, R.; Raessi, M. Evaluation of Diesel Spray-Wall Interaction and Morphology around Impingement Location; SAE Technical Paper 2018-01-0276; SAE International: Warrendale, PA, USA, 2018. [CrossRef] 